\title{
Ressenya
}

\section{Beatrice Heuser}

Brexit in History: Sovereignty or a European Union?

Londres, Hurst \& Company, 2019, $301 \mathrm{p}$.

ISBN: 978-1787381261

\author{
Nil Bosch Navarro \\ Universitat Autònoma de Barcelona \\ nil.bosch@uab.cat \\ ORCID: 0000-0003-1944-8887
}

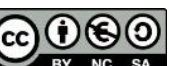

Recepció: juliol 2021

Acceptació: juliol 2021

Publicació: gener 2022

Cita recomanada: HEUSER, B. Brexit in History: Sovereignty or a European Union? (Hurst \& Company, 2019), rec. BOSCH NAVARRO, N., Quaderns IEE: Revista de l'Institut d'Estudis Europeus, 1 (1) (2022), 218-222. - DOI «https://doi.org/10.5565/rev/quadernsiee.10»

El 31 de gener de 2020 el Regne Unit va deixar de ser membre de la Unió Europea (UE), fruit del resultat del referèndum celebrat el 23 de juny de 2016 en què l'opció de Sortir de la $U E$ va vèncer amb el 51,9\% dels vots. Ha estat un fet històric excepcional, amb problemes encara oberts, i trencador: podria ser el final de dècades de tendència de sumar nous membres al projecte supranacional europeu?.

Més enllà de l'anàlisi al que ens tenen acostumats els mitjans sobre el Brexit, basat en un ventall temàtic d'impacte més recent, la ciència històrica ha tractat de donar-hi una resposta des de la longue durée. Trobem exemples com Menno Spiering (2015), que adopta una perspectiva d'anàlisi cultural sobre la història de l'euroescepticisme britànic; el cas de Brendan Simm (2016), que el mateix any del referèndum va optar per un enfocament que es remunta fins a l'alta edat mitjana; o David Reynolds (2019), que analitza la influència de la història en l'ideari del Brexit. D’altres com el col-lectiu Historians for Britain proposen una visió genuïna, idealista i diferenciada de la història britànica respecte a la resta d'Europa, amb el focus posat en l'Imperi, la Segona Guerra Mundial, Waterloo, Isabel I o «el primer Brexit» d'Enric VIII (Heuser, 2019: 72). Per a aquest corrent interpretatiu, que compta amb polítics com el conservador Rees Mogg, el Brexit hauria estat un pas natural donades les característiques singulars de la història del Regne Unit.

Beatrice Heuser transcendeix la resta de treballs científics amb una major amplitud cronològica i dona una visió objectiva de la història que supera el 
romanticisme de la pseudo-historiografia nacionalista. L'autora ens presenta un doble propòsit: per una banda, es planteja traçar els orígens de les idees que han donat lloc al Brexit. Per altra banda, el llibre és una contribució acadèmica que analitza la teoria de les relacions internacionals des d'un punt de vista analític dels fets que van ocórrer i de les percepcions i projectes que se'n tenien.

Per tant, la seva aportació es realitza des de l'estudi de les relacions internacionals, estructurada a partir de la dialèctica conformada pels intents d'unificar Europa sota un ordre comú de diverses formes, tant en el pla teòric com factual, i les tendències a refermar la sobirania nacional dels estats, d'entre les quals el Brexit n'és l'últim exponent. En aquest marc s'exposa com una sèrie de pensadors van intentar idear sistemes per establir relacions pacífiques entre els estats europeus. Per sorprenent que pugui semblar, tot això es planteja sense abordar directament el Brexit, per la qual cosa, el títol pot dur a equívocs sobre el seu contingut, si s'espera una anàlisi més convencional.

El llibre comença per preparar el lector amb un repàs teòric de conceptes i una crítica al seu ús inexacte, des de corrents interpretatives de les relacions internacionals, com el realisme, fins a convencionalismes, com el terme estat-nació, que Heuser troba més propi d'un programa polític que d'una anàlisi objectiva de la realitat (Heuser, 2019: 32). Així mateix, introdueix el leitmotiv que com una cadena d'ADN estructura tot el llibre: la pugna entre la reafirmació de la sobirania dels Estats a actuar sense límits i l'establiment de sistemes o entitats supranacionals que la limitin. Al llarg de la història ha pres la forma d'un equilibri entre els Estats i la seva independència o la preeminència d'una monarquia universal. Posteriorment, en època contemporània, ha evolucionat entre nous sistemes de cooperació per intentar crear relacions pacífiques $\mathrm{o}$, com a mínim, estables, i sistemes de relacions de caràcter oligàrquic en què unes poques potències dictaminen el destí del conjunt dels estats.

El contingut cerca els orígens d'aquests preceptes en l'Edat Antiga, durant la Grècia clàssica, període convuls en què es van gestar termes com la sobirania, la guerra civil, la llibertat, les aliances, i conceptes com la noció de sobirania. Amb l'Imperi romà va incorporar-se la Pax Romana, concepció que esgrimia que l'Imperi era un espai d'ordre i pau en contraposició amb l'exterior poblat pels bàrbars. Durant l'Imperi tardà, amb l'adopció del cristianisme, van sumar-se les concepcions teològiques de la tradició israelita. Aquest marc continuarà durant l'Edat Medieval en la pugna entre establir un Imperi universal cristià, encapçalat pel Sacre Imperi, i la reafirmació de les diferents monarquies europees, que aspiraven a ser tractades com a iguals amb l'Imperi. La noció de comunitat cristiana o christianitas, promoguda pel papat, tractava d'ordenar la violència i el conflicte a través de pautes regulades d'actuació en l'acció exterior i interior dels països, mentre que el dualisme de la Pax Romana va traslladar-se al pla religiós amb la confrontació amb l'Islam.

Amb l'adveniment de l'Edat Moderna s'observa un trencament amb la tradició anterior: la Reforma i la Pau de Westfàlia (1648) van comportar la ruptura de la legitimitat de l'església per articular un sistema cristià que regulés els conflictes i la preeminència del Sacre Imperi. En el seu lloc van consolidar-se els estats absolutistes, 
amb plens poders per decidir sobre la guerra i la pau, i en constant pugna entre ells per l'hegemonia a Europa i a les colònies. En aquest context, els estats es vigilaven constantment perquè cap d'ells acumulés massa poder, en un equilibri molt precari. Les aliances cercaven limitar aquells estats que aspiraven al domini del continent, com per exemple França amb Lluís XIV, que va haver de fer front a la Lliga d'Augsburg (1689). Aquest sistema d'equilibri, conegut com a Balance of Power, va consolidar-se durant el segle XVIII, a partir de la Pau d'Utrecht (1713-1715). El seu final se situa en les Guerres Napoleòniques, que van ser la culminació de la pugna entre les dues visions d'Europa, com també assenyala Brendan Simm (Heuser, 2019: 144).

Amb l'Edat Contemporània s'inicien els sistemes oligàrquics de potències i els intents de cooperació internacional. El Congrés de Viena (1815) va donar lloc a la pentarquia de les Grans Potències, cinc grans països que dictaven el destí de les relacions internacionals, encara que va ser trencada per l'auge del nacionalisme i l'imperialisme. La Primera i la Segona Guerra Mundial van donar lloc a dos intents de crear un ordre universal que inclogués tot el món: la Societat de Nacions i l'Organització de les Nacions Unides. Ambdues van estar caracteritzades per reproduir un sistema oligàrquic, en el qual cinc grans potències tenen un pes superior a la resta de membres. La nota diferencial la va aportar la integració europea, basada inicialment en diverses iniciatives, en les quals el Regne Unit va participar activament, malgrat quedar inicialment al marge de la que va acabar sent la principal, la Comunitat Econòmica Europea.

Paral-lelament a l'anàlisi del sistema internacional i de la seguretat, s'exposa com davant de la conflictiva trajectòria dels estats europeus una sèrie de pensadors van idear sistemes per regular les relacions entre els estats i evitar la guerra. Beatrice Heuser traça com des de l'any 1305 personalitats com Pierre Dubois, George Podiebrad, William Penn o Jeremy Bentham, fins als casos més recents d'Aristide Briand i Coudenhove-Kalergi, van fer propostes per establir un sistema de relacions pacífiques a Europa, sota formes confederals, federals i associatives. Tot i que la majoria d'iniciatives no van plasmar-se a efectes pràctics, van tenir una influència decisiva en la conformació de tractats de pau, sistemes internacionals, preceptes de la política exterior i en la formació de la UE.

Així doncs, sense abordar directament el Brexit, Beatrice Heuser és capaç de mostrar com aquest fet s'insereix en una dinàmica plurisecular que forma part d'una pregunta més amplia en la història europea: s'ha d'implantar un model supranacional o els estats han de reafirmar els seus drets sobirans? L'escala temporal triada per l'autora sens dubte mostra com al llarg de la història s'ha produït aquesta dicotomia, des de l'antiga Grècia fins avui, passant pel Sacre Imperi i altres intents d'ordre universalista. Així mateix, la validesa del marc cronològic es posa de manifest en l'aparell crític de l'obra, en què es mostra com aquesta pregunta s'ha retroalimentat a si mateixa a través dels intel-lectuals i del personal polític de cada època.

D'aquesta manera, el llibre és un recordatori que aquesta pregunta, de resposta oberta, ha tornat a estar present amb el Brexit. A diferència de treballs focalitzats a partir de 1945 o la historiografia nacionalista, Beatrice Heuser traça una via pròpia per 
entendre i situar el Brexit en un marc més ampli des d'una perspectiva crítica. El llibre mostra com el Regne Unit ha estat un estat més d'Europa, tot i que com reconeix l'autora, períodes com la resistència durant la Segona Guerra Mundial o la Splendid Isolation han marcat decisivament la memòria col-lectiva britànica (Heuser, 2019: 156). També desmenteix, amb ironia, supòsits actuals com la Special Relationship amb els Estats Units i la Commonwealth, més adequats a vincles simbòlics i dependents de la benevolència nord-americana que d'una relació estructurada (Heuser, 2019: 207). Per a Beatrice Heuser, convé recordar davant d'aquestes tendències que el Regne Unit no pot ignorar el que passi al continent com l'any 1939: «... Britain learnt at a great cost that events in Europe could not be ignored...» (Heuser, 2019: 235).

Una mostra d'aquesta participació és la tria que fa l'autora dels principals pensadors: una part significativa provenen de l'àmbit britànic, com Jeremy Bentham i William Penn. L'amplitud de la perspectiva que s'adopta per encabir personatges de països i èpoques tan diverses mostra com es pot adoptar un enfocament diferent de la història de la integració europea, sovint caracteritzat per una visió teleològica que parteix de Schumann i Monnet i que situa la seva gènesi l'any 1945. En aquest sentit, l'autora se situa en la línia del projecte del Labex-EHNE, que té l'objectiu d'escriure una nova història d'Europa i amb el qual Beatrice Heuser ha mantingut intercanvis científics.

Així mateix, pel que fa a la combinació de la història amb les relacions internacionals, s'opta per una visió centrada en la seguretat. S'ha de tenir present que l'autora és un referent en els estudis estratègics: la seva trajectòria acadèmica s'ha centrat en l'anàlisi dels conflictes, de les percepcions sobre les guerres i de les relacions internacionals dels estats europeus. De fet, el llibre és la síntesi de més de vint dècades de publicacions en aquest àmbit (Heuser, 2017; 2010; 2001). Aquest enfocament és encertat per donar coherència al conjunt de l'obra, ja que la dota d'un fil conductor molt clar malgrat haver d'incloure períodes històrics molt diferents. Tot i això, pot negligir altres àrees necessàries per donar una visió més completa del conjunt.

En conclusió, Brexit in History: Sovereignty or a European Union? és un text útil per reflexionar sobre el Brexit des d'una perspectiva més àmplia. És una proposta que es diferencia fonamentalment per situar aquesta problemàtica en un marc històric molt llarg, tractat amb una perspectiva objectiva i rigorosa i amb un aparell crític ric. Si bé la pregunta que planteja amb el títol té una resposta oberta, Beatrice Heuser mostra amb evidències que la dinàmica de refermar la sobirania ha estat la base de les conflictives relacions entre els països europeus. Una solució possible que aporta són les estructures que permeten les consultes multilaterals. L'autora assenyala, a través de Churchill, com la UE, malgrat la necessitat de reconsiderar-se i reformar-se, «it is the worst form of government for this continent except for all others that have been tried» (Heuser, 2019: 235). 


\section{REFERÈNCIES}

Heuser, B. (2017). Strategy Before Clausewitz: Linking Warfare and Statecraft, 14001830. Abingdon; Routledge.

Heuser, B. (2010). The Evolution of Strategy: Thinking War from Antiquity to the Present. Cambride: University Press.

Heuser, B.; Hartmann, A. V. (2001). War, Peace and World Orders in European History. Londres: Routledge.

Reynolds, D. (2019). Island Stories: Britain and its History in the Age of Brexit. Glasgow: Harper Collins.

Simm, B. (2016). Britain's Europe. A thousand years of conflict and cooperation. Londres: Penguin History.

Spiering, M. (2015). A cultural history of British Euroscepticism. Londres: Palgrave Macmillan UK. 